\title{
Turnover feminino nas cooperativas de resíduos sólidos: um estudo fenomenológico sobre as causas
}

\section{RESUMO}

Este trabalho busca compreender as causas do turnover voluntário em um conjunto de cooperativas de resíduos sólidos, situadas no interior do estado de SãoPaulo. Para tanto, aplica-se o método da fenomenologia hermenêutica, identificando através da análise de entrevistas realizadas com mulheres ex-cooperadas, quais os motivos para o fenômeno da desistência do trabalho nestas unidades analisadas. Os fatores que emergiram das experiências relatadas referem-se às dificuldades, expectativas e insatisfações vivenciadas por estes agentes. Busca-se, através deste estudo, conhecer elementos que contribuam para o alinhamento de medidas estratégicas às necessidades das cooperadas, ampliando seu grau de comprometimento e fortalecendo o processo de inserção social presente nos objetivos das cooperativas de resíduos sólidos.

Palavras-chave: Cooperativa. Resíduo. Sólido. Desistência do trabalho. Turnover. Fenomenologia.

Joelma Telesi Pacheco Conceição joelma.telesi@gmail.com Mestra em Administração de Empresas Faculdade Campo Limpo Paulista

Márcio Magera Conceição magera@uol.com.br Doutor em Administração Faculdade Campo Limpo Paulista

Alexandre Martinewski martinewski@gmail.com 


\section{INTRODUÇÃO}

As condições de inserção social por meio da oferta de trabalho formal, no atual mercado competitivo, são precárias e desiguais, afetando negativamente um percentual de trabalhadores com menor grau de instrução e qualificação. A falta de oportunidades de trabalho conduz essa parcela excluída para a execução de serviços terceirizados e informais, atividades crescentes em todos os setores da economia (ANTUNES, 2005; DIEESE, 2011).

Aproximadamente 1 milhão de pessoas em todo o Brasil, busca sobrevivência trabalhando na coleta de lixo, muitos atuando individualmente em situação precária, expostos a riscos e contaminação (CEMPRE, 2012). As cooperativas de resíduos sólidos contribuem para a inserção desta parcela marginalizada de trabalhadores, atrelando geração de oportunidades de trabalho e renda às iniciativas que minimizem os problemas ambientais (MAGERA, 2013; PAULA; SOUZA-PINTO; SOUZA, 2010; WIEGO, 2009).

Nos últimos séculos, a população mundial saltou de 1 bilhão de habitantes, em 1800, para 7 bilhões em 2011, fator que contribuiu para o aumento do consumo e, consequentemente, para a maior produção de resíduos. O aumento do consumo de produtos industrializados e o desenvolvimento tecnológico têm contribuído para que a atual produção de resíduos seja 350 vezes maior do que o volume gerado pela população antes da Revolução Industrial (MAGERA, 2005).

Em 2010, o volume de resíduos sólidos gerados no Brasil foi de 60,8 milhões de toneladas, número 6,8\% superior ao volume gerado em 2009. Enquanto volumes crescentes de resíduos saturam depósitos e aterros, programas de gestão e destinação correta de resíduos mantêm-se insuficientes. Até 2010, dos 5564 municípios brasileiros, apenas 3.205 implantaram o sistema de coleta seletiva (ABRELPE, 2010).

A relação entre poluição, saúde pública e a necessidade de ampliar a oferta de trabalho, ocasionaram a mobilização de autoridades, organizações não governamentais (ONG) e associações na busca por alternativas. Soluções sustentáveis tornaram-se uma tendência global e fazem parte de pesquisas e ações organizacionais, que impactam no sucesso e visibilidade dos negócios, como estratégias que possibilitam vantagens competitivas (BERNS et al., 2009).

No Brasil, as iniciativas ligadas ao meio ambiente foram estruturadas após a Conferência das Nações Unidas sobre Meio Ambiente e Desenvolvimento, realizada na cidade do Rio de Janeiro, em 1992 (ECO 92). A união de líderes mundiais neste encontro resultou na elaboração de um documento denominado "Carta da Terra", contendo princípios e metas básicas que envolvem a proteção dos recursos da Terra através de estratégias direcionadas para medidas econômicas, sociais e ambientais. O que se observa, após mais de 20 anos, é que o evento foi mais midiático do que efetivo nas suas propostas, pois grande parte dos compromissos traçados na Eco 92 não se converteram em ações.

Após a aprovação da Política Nacional de Resíduos Sólidos (PNRS), em 2010, pelo Congresso Nacional, as cooperativas de resíduos sólidos vêm recebendo atenção, incentivo e pesquisas que, em sua maioria, avaliam seu sistema de funcionamento e gestão, além de um tratamento adequado dos resíduos sólidos e metas de inclusão social, através da criação de oportunidades de trabalho. Assim como ocorre no Brasil, outros países como a Colômbia, a Argentina, o Peru e a Índia, também atrelaram as atividades de inclusão social às iniciativas ambientais (WIEGO, 2009).

O cooperativismo no Brasil, ligado ao segmento de triagem dos resíduos sólidos (RS), é recente e ganhou força na segunda metade dos anos de 1990, assim como as políticas de logística reversa associadas a ele, que ainda estão sendo compreendidas e desenvolvidas pela sociedade brasileira (SINGER, 2002).

As pesquisas sobre as cooperativas de resíduos sólidos, como as realizadas por Krikke, Van Harten e Schuur (1998) e Magera (2005), apontam seus objetivos na promoção de alternativas para a gestão de resíduos, iniciativas para a geração de renda e consequentes melhorias na qualidade de vida dos associados, em sua maioria ex-catadores de resíduos recicláveis. Singer (2002) salienta que os empreendimentos sociais vêm se tornando uma opção importante para muitos excluídos do mercado de trabalho, beneficiando tanto esses trabalhadores quanto a comunidade onde este empreendimento está inserido. No entanto, são vários os desafios encontrados nesse processo, entre eles, o fenômeno da desistência do trabalho nas cooperativas, que conduz à rotatividade, neste trabalho tratada como turnover voluntário. 
Joelma Telesi Pacheco Conceição; Márcio Magera Conceição; Alexandre Martinewski

A elevada rotatividade nas cooperativas de resíduos sólidos (RS), foi identificada por outros autores em pesquisas sobre cooperativas RS situadas nas cidades de Itatiba (SP) (GAMA; KODA, 2010), na capital São Paulo (COUTO, 2012; SALGADO; TEIXEIRA, 2012; SOUZA; PAULA; SOUZA-PINTO, 2012) e em Santo André (SP) (LIMA, 2011). No entanto não foi desenvolvida nenhuma pesquisa para a descrição de suas causas.

Esta pesquisa, de natureza qualitativa, analisou sete cooperativas RS localizadas nas cidades de Campinas (SP), Salto (SP) e de Paulínia (SP), que apresentam como gargalo à sua produtividade, um elevado turnover de seus associados. Buscando entender suas causas, foram realizadas entrevistas com ex-cooperadas através do método fenomenológico, por se tratar de uma estratégia de investigação que busca, partindo da interrogação sobre os fenômenos vivenciados, compreender a essência das experiências humanas. "A filosofia fenomenológica da mente toma a subjetividade como ponto de partida, tanto no plano lógico ou epistemológico, como no metodológico" (CESCON, 2013, p. 83).

A identificação das principais causas que conduzem à elevação da rotatividade, pela desistência da atividade nas cooperativas, busca contribuir para o planejamento de ações e estratégias que ampliem o processo de retenção dos cooperados. Segundo o Dicionário Michaelis, o significado atribuído à palavra desistência é: abandono, abdicação, deserção, renunciação e resignação. Foi caracterizado como desistência o afastamento do trabalho pelo associado que, na maioria das vezes, ocorre sem a apresentação de uma justificativa ou causa para sua atitude.

Segundo administradores das cooperativas analisadas, a permanência de profissionais por períodos maiores, contribui para o fortalecimento do vínculo com a equipe, proporciona maior produtividade pela experiência adquirida e garante maior abrangência nas funções sociais presentes nos princípios das cooperativas, que objetivam a geração de renda e inclusão, para uma parcela da população com poucas oportunidades de trabalho no mercado formalizado (COPERLÍNEA AMBIENTAL DO BRASIL, 2013; CRCA, 2012).

\subsection{Objetivo geral}

Este estudo teve como objetivo compreender as causas que motivaram a desistência do trabalho pelos ex-cooperados do sexo feminino, que compõe a maioria dos integrantes das cooperativas analisadas. Buscou-se resgatar a experiência vivida pela visão dos atores geradores do fenômeno da desistência, já que para este grupo de pessoas, as oportunidades no mercado formal cada vez mais competitivo, são escassas, o que ocasiona a busca por sobrevivência através de atividades que colocam em risco sua saúde, bem-estar e segurança.

No Brasil, as cooperativas RS foram criadas por iniciativa de entidades assistenciais ligadas às comunidades da igreja católica, com o objetivo de proporcionar uma melhoria na vida de pessoas que sobrevivem precariamente da coleta individual de materiais recicláveis, proporcionando melhores oportunidades de ganhos através do empoderamento proporcionado pelo trabalho coletivo. No entanto, de acordo com os dados apontados pelos administradores destas cooperativas, parte dos associados que ingressam como cooperados, desistem do trabalho no período inferior a um ano. A melhor evidência deste fato é a elevada taxa de turnover voluntário destas sete entidades, que conforme dados analisados, atingiu uma média próxima de 25\% nos anos de 2010 a 2013 (COPERLÍNEA AMBIENTAL DO BRASIL, 2013; CRCA, 2012).

Para a realização deste estudo, foram contabilizados apenas os cooperados que se desligaram voluntariamente, já que o foco do estudo é entender as percepções e razões que determinaram o fenômeno da desistência do trabalho por este grupo específico de profissionais.

Segundo informações fornecidas pelos administradores das cooperativas RS analisadas, enquanto o turnover voluntário apresenta taxas elevadas, raramente ocorre o desligamento de um cooperado por iniciativa da cooperativa. Um cooperado só é levado a deixar a cooperativa se fizer algo grave, que venha a ferir o Estatuto Interno (envolvimento em conflitos graves, incapacidade para o trabalho motivada por vício, roubo) e isso ocorre em proporções muito menores do que o turnover voluntário.

O turnover ou rotatividade, quando aplicada ao mercado de trabalho, representa a substituição do ocupante de um posto de trabalho por outro, ou seja, a demissão (voluntária ou involuntária) seguida da admissão, em um posto específico, individual, ou em diversos postos, envolvendo vários trabalhadores (DIEESE, 2011). 
São crescentes as pesquisas sobre turnover e a busca pela compreensão de suas causas intriga administradores e estudiosos do comportamento humano em muitos países (VANDENBERG, 1999), pois a perda de um profissional para o mercado de trabalho, tornou-se um fator relevante a medida que os profissionais agregam valor às empresas, não pelo cargo que ocupam, mas pelo seu potencial de inserção nos contextos de desenvolvimento das empresas.

Valores elevados de turnover sugerem problemas relacionados à empresa, possivelmente produto de um clima organizacional inadequado ou política salarial defasada, enquanto valores muito baixos, contém fatores negativos por indicar pouca diversificação da equipe (BACHMANN \& ASSOCIADOS, 2011).

O turnover pode ser favorável quando os profissionais improdutivos são excluídos da organização e são substituídos por pessoas que apresentam melhor desempenho (VANDENBERG, 1999). No entanto, a perda de um profissional, na maioria das vezes, ocasiona algum grau de prejuízo para a organização pela perda do capital intelectual, pois parte dos investimentos realizados para o treinamento e capacitação da equipe de trabalho, é perdida quando ocorre o desligamento de um profissional, que leva consigo experiência e conhecimento que não convergiram para a empresa e que podem vir a beneficiar organizações concorrentes.

As elevadas taxas de rotatividade são um problema que afeta o funcionamento do mercado de trabalho, interferindo na produtividade e no clima organizacional. Entender os motivos que promoveram o turnover pode contribuir para a retenção de talentos e retorno em investimentos com treinamento e qualificação (VANDENBERG, 1999; LEE; MITCHELL, 1994).

O estudo das causas do turnover voluntário, através da compreensão dos motivos e intenções que levam o cooperado a desistir do trabalho nas cooperativas de resíduos sólidos, apresenta-se como um fenômeno que deve ser melhor compreendido, visando apontar medidas que possibilitem a ampliação dos resultados para as cooperativas no que se refere à geração de oportunidades de trabalho e melhorias na qualidade de seus serviços pelo aumento do potencial produtivo e maior satisfação com o trabalho.

O trabalho realizado nas cooperativas de resíduos, depende basicamente da atividade de triagem realizada pelos cooperados, que conforme adquirem conhecimento e experiência, ganham maior desenvoltura e rapidez na realização de todos os processos necessários ao manejo dos produtos. O uso de maquinários nas unidades estudadas é praticamente inexistente, bem como os recursos financeiros para adquiri-los. Portanto, a presença de cooperados experientes é fundamental para a agilidade necessária ao processo. Quando ocorre o turnover percebe-se, segundo relatos dos próprios cooperados, que o ritmo de trabalho reflete menor produtividade e rendimento, conforme constatado na pesquisa in loco deste estudo.

\subsection{Objetivos específicos}

Para a realização do estudo, foram entrevistadas 30 ex-cooperadas, das sete unidades analisadas, número que representa uma média aproximada de indivíduos, do sexo feminino, que se inserem e deixam a cooperativa mensalmente.

Os participantes da pesquisa são mulheres que desistiram da atividade de cooperada no período inferior a um ano na função, após a permanência mínima de seis meses na cooperativa, durante os anos de 2010, 2011, 2012 ou 2013. Buscou-se, portanto, ex-cooperadas que vivenciaram o fenômeno estudado num período relativamente recente.

Os contatos com as entrevistadas foram obtidos de duas formas: através de fontes primárias, nomes e endereços de indivíduos, fornecidos pelas cooperativas analisadas e através de fontes secundárias, resultantes de indicação dos primeiros ex-cooperados contatados. A participação de indivíduos indicados pelos próprios ex-cooperados contribuiu para ofertar maior credibilidade e neutralidade à pesquisa, por possibilitar a participação de pessoas cujos nomes poderiam ter sido omitidos pelas cooperativas, a fim de ocultar informações comprometedoras.

As cooperativas analisadas se constituem, em sua maioria (aproximadamente 65\%), de mulheres casadas ou amasiadas e com filhos, chefes de família, com faixa etária entre 30 e 40 anos. Grande parte das entrevistadas, assim como cooperados que compõem as unidades estudadas, antes de se associarem às cooperativas já atuaram individualmente como catadores de recicláveis, e devido a pouca escolaridade e baixa qualificação profissional 
Joelma Telesi Pacheco Conceição; Márcio Magera Conceição; Alexandre Martinewski

da qual dispõem, sobrevivem de subempregos, atividades clandestinas, onde permanecem submetidos à baixa remuneração, inferior ao salário mínimo vigente no país, expostos a uma realidade permeada de dificuldade para obtenção de sobrevivência.

As cooperativas RS têm como objetivo apoiar o catador individual de recicláveis, que se expõe a todo tipo de contaminação e risco ao realizar o trabalho de coleta de resíduos de maneira inadequada, obtendo baixos rendimentos pelo pouco volume agregado de seu trabalho. A oportunidade de deixar as ruas e o trabalho individual e informal, deveria acrescentar maiores ganhos e segurança às mulheres, suficientes para estabelecerem um vínculo mais forte com as demais associadas, que se refletisse na identificação e permanência por maior tempo nas cooperativas, onde exercem a função de triadoras.

A função do triador, desempenhada nas cooperativas, comparada à tarefa do catador individual de recicláveis, tem entre seus objetivos prioritários oferecer vantagens para tornar o trabalho nas cooperativas RS mais atrativo, fator resultante do cuidado com alguns aspectos:

- A segurança de um local com infraestrutura adequada para o trabalho, longe das ruas, nas quais o catador se depara com problemas para transportar o material coletado;

- A oferta de treinamento, capacitação operacional e técnica, além de orientações sobre aspectos administrativos que envolvem o trabalho como cooperado;

- A melhor qualidade dos produtos manipulados, pela baixa contaminação, pré-seleção e separação dos resíduos orgânicos;

- A organização, instrução e colaboração para a realização de um trabalho em equipe;

- O uso de Equipamentos de Proteção Individual (EPI), que protegem o trabalhador de possíveis acidentes e de equipamentos adequados para o enfardamento, como prensa e empilhadeira, que demandam menor esforço e desgaste físico na execução das tarefas;

- O resgate da cidadania e dignidade por pertencer a um grupo e participar democraticamente de decisões de gestão.

A denominação de triador, utilizada neste trabalho, bem como, no ambiente das cooperativas RS analisadas, refere-se ao profissional que faz a classificação dos resíduos dispostos nas cooperativas, de acordo com suas propriedades. Principal ator neste processo, o triador é o agente responsável por realizar a classificação mais fina dos materiais recicláveis, de acordo com suas características e composição. De acordo com a Classificação Brasileira de Ocupações (CBO), número 5192, estes profissionais são denominados: catador de material reciclável; selecionador de material reciclável ou operador de prensa de material reciclável e têm como responsabilidade: coletar material reciclável e reaproveitável; vender material coletado; selecionar material coletado; preparar o material para expedição; realizar manutenção do ambiente e equipamentos de trabalho; divulgar o trabalho de reciclagem; administrar o trabalho e trabalhar com segurança (BRASIL, 2013).

No entanto, nem sempre estas vantagens estão presentes em todos os seus aspectos nas cooperativas RS. É comum haver unidades que não oferecem EPI ou equipamentos adequados para manuseio e remoção dos resíduos, operando sem infraestrutura adequada, levando os cooperados a executar grande parte das suas funções com demasiado esforço físico e exposição à contaminação pelo contato inadequado com os resíduos (LIMA, 2011).

As dificuldades na execução do trabalho como triador impõe inúmeros desafios aos associados, que podem ser resultantes de condições físicas, do preconceito vinculado ao trabalho com resíduos, de inadequações na estrutura local (interna e externa) e até mesmo questões políticas ou comportamentais. Para entendê-las foi utilizada a abordagem fenomenológica, procurando seguir uma sequência de passos para a coleta de dados (CRESWELL, 1998), iniciada pela entrevista em que, através da linguagem reconstitui a experiência vivida do entrevistado sobre o fenômeno estudado (MARTINS, 1992), procurando "levar a pessoa entrevistada a descrever e refletir sobre a experiência vivida no contexto de sua vivência" (SILVA, 2010, p. 280).

Para tanto, buscou-se aplicar requisitos recomendados pela fenomenologia, no qual durante a aplicação da entrevista, o entrevistado deve receber toda a atenção por parte do entrevistador, mantendo-se a concentração e o diálogo no contexto da experiência (VAN MANEN, 1990).

Segundo a fenomenologia, ao aplicar a entrevista o pesquisador deve se "abster de emitir juízos, apenas permanecer atento ao que está sendo relatado" (SORDI, 2013, p. 18). Tal postura, denominada pelo termo 
epoché, tem por objetivo não interferir nas opiniões e percepções que estão sendo descritas pelo entrevistado e isolar o fenômeno estudado de qualquer preconceito ou pressuposições já concebidas por parte do pesquisador, assumindo uma atitude natural, interpretando comportamentos objetivamente, controlando o impacto de observador e suspendendo qualquer hipótese que antecipe a realidade da investigação (CESCON, 2013; MERIGHI; GONÇALVES; FERREIRA, 2007; WAUGH JR.; WAUGH, 2004). Esta postura de busca pela verdade permite liberar os significados encobertos, dando espaço ao surgimento do eidos, que compõe a essência do fenômeno investigado (VAN MANEN, 1990).

\subsection{Fenomenologia}

Para a realização desta pesquisa, optou-se pelo método da fenomenologia hermenêutica, por tratar-se de um procedimento que vem sendo aplicado às pesquisas na área de Desenvolvimento de Recursos Humanos, e também por proporcionar uma investigação direta, que ajuda a explicar a experiência humana em sua essência, de maneira holística (GIBSON, 2003).

Segundo a fenomenologia, a realidade se constrói a partir da experiência de atores envolvidos, com "foco no relato das experiências vividas e não no referencial teórico, caracterizando assim, um paradigma construtivista" (SORDI, 2013, p. 18).

O método fenomenológico hermenêutico tem início através da coleta de dados, obtidos pela aplicação de entrevistas. Os procedimentos fenomenológicos são relevantes para: a compreensão da essência da experiência humana, a compreensão de sua complexidade para o estabelecimento de diretrizes planejadas a partir de aspectos mais próximos da realidade e expectativas dos indivíduos.

O termo Fenomenologia significa discurso sobre aquilo que se mostra como é, e se propõe a desvelar algo que está oculto, sem que os princípios preestabelecidos do pesquisador influenciem a investigação sobre o tema, mantendo-se livre de julgamentos e pressupostos (APPOLINÁRIO, 2012; CRESWELL, 2010). É constituída pelos termos gregos phainomenon, que significa uma aparição, aquilo que se mostra e logos que significa o estudo, a razão, o discurso (APPOLINÁRIO, 2012).

As raízes filosóficas da fenomenologia são fruto do trabalho de Edmund Husserl (1859 - 1938), frequentemente chamado de 'pai da fenomenologia pura'. Husserl concluiu que a atividade de consciência e os objetos de pensamento consciente são aspectos inseparáveis da experiência humana. "A consciência do ser humano e a própria realidade são partes interligadas de um todo" (APPOLINÁRIO, 2012, p. 169).

Husserl exaltou a importância das interpretações subjetivas para compreensão da realidade e, buscando entendê-la a partir do significado dos fenômenos para os sujeitos (WAUGH JR.; WAUGH, 2011). A intenção foi estabelecer uma base epistemológica para a filosofia, que a convertesse em uma ciência do rigor (BOAVA; MACEDO, 2011).

Para a fenomenologia, a consciência não opera no vazio, porém seu fundamento está centrado na busca pelos significados das experiências que chegam à consciência (noema) através da percepção (noesis) (BOAVA; MACEDO, 2011).

A partir do trabalho de Husserl sobre a fenomenologia, o filósofo alemão Heidegger (1889-1976) desenvolveu um método fenomenológico que se ocupa de compreender os significados da natureza das experiências subjetivas de determinado fenômeno social, de natureza individual, buscando interpretar ou articular a compreensão pré-ontológica do ser: "[...] a fenomenologia heideggeriana busca interpretar nossa atividade diária [...] de modo a tornar manifesta as estruturas da inteligibilidade, em grande parte implícitas, que caracterizam essa atividade" (CERBONE, 2013, p. 73).

Outros estudiosos contribuíram com a fenomenologia, como: Jean-Paul Sartre; Maurice MerleauPonty; Simone de Beauvoir; Hannah Arendt; Emmanuel Levinas, propondo novas tendências, ampliando e transformando os conceitos iniciais sobre fenomenologia a partir da obra de Heidegger "Ser e tempo", de 1927 (BOAVA; MACEDO, 2011).

Em 1939, Alfred Shutz (1899-1959) levou os conceitos da fenomenologia para os Estados Unidos, tornandose a figura central do movimento fenomenológico americano. Na década de 1970, o movimento ganhou força, questionando a racionalidade, apoiado pela preocupação crescente sobre a parcialidade do positivismo lógico, 
Joelma Telesi Pacheco Conceição; Márcio Magera Conceição; Alexandre Martinewski

questionado pelos fenomenólogos por não oferecer ferramentas filosóficas e, como consequência, excluir as necessidades práticas da sociedade (WAUGH JR.; WAUGH, 2004).

\subsection{Procedimentos realizados}

A coleta de dados ocorreu após aplicação das entrevistas individuais, iniciadas a partir de uma pergunta norteadora aberta, proposta igualmente a todas as entrevistadas: $\mathbf{O}$ que motivou a desistência do trabalho na cooperativa?

Todas as entrevistas foram gravadas e depois transcritas gerando registros que corresponderam ao ponto de partida na trajetória desta pesquisa fenomenológica. O nome das entrevistadas foi preservado e substituído por um nome fictício e adotou-se um código de identificação para a análise das informações. As transcrições foram realizadas na íntegra, de acordo com procedimentos de transcrição Ipsis literis, segundo critérios da Sociolinguística Variacionista Laboviana (LABOV) - (TARALLO, 1986), como se pode observar nos trechos de relatos das ex-cooperadas citados no próximo capítulo.

Para verificação do material registrado, foi utilizada a técnica da análise de conteúdo, baseada nos estudos de Bardin (2011), que utiliza-se da organização como item primordial da pesquisa. Os procedimentos de análise ocorreram em três etapas:

- A pré-análise, pela leitura e releitura dos relatos e organização das informações coletadas, reescrevendo os dados contidos no texto de forma mais sintetizada e objetiva, segundo a questão proposta pela pesquisa. Foram criados parágrafos resumidos, identificados como unidades de significado;

- A exploração do material, através da definição de frases que simplificam o tema disposto na unidade dignificado de forma compacta. Estas frases receberam a denominação de categorias;

- Tratamento dos resultados pela interpretação com a busca de similaridades contidas nas categorias, com o objetivo de agrupar informações semelhantes.

Buscou-se, através dos registros, identificar de cada ex-cooperada, o principal motivo para a desistência do trabalho dentre as várias dificuldades relatadas sobre as experiências vivenciadas durante a atividade de cooperado.

As análises ocorreram pelo processo de leitura, releitura e observação das entrevistas das ex-cooperadas. O objetivo desse processo foi identificar dados emergentes de cada entrevista, com foco na interpretação dos discursos segundo a questão da pesquisa, captando os significados presentes nas falas e associando trechos dos relatos das pessoas a temas, buscando uma visão sistêmica das experiências relatadas (SORDI, 2013; SILVA, 2010).

As informações coletadas foram analisadas inicialmente de forma individual. É comum que as entrevistas, ao serem transcritas na íntegra, tragam diversos temas, alguns desinteressantes para o estudo, que precisam ser filtrados, mantendo-se apenas os fatos mais relevantes. Com este objetivo, cada uma das 30 entrevistas foi sintetizada e suas informações foram convertidas em "categorias". As "categorias" são frases que resumem o fato informado de maneira objetiva e prática para a realização da análise fenomenológica.

Após a análise individual, teve início a análise conjunta das "categorias" obtidas a partir das 30 entrevistas. Esta etapa da análise ocorreu de duas formas:

- De acordo com suas similaridades: algumas categorias se repetiram em diversas entrevistas, resultado de percepções semelhantes, sendo então agrupadas.

- Segundo a questão da pesquisa: cada entrevista transcrita teve, dentre as categorias criadas, o destaque para a categoria mais significativa, apontada com maior ênfase e relevância, como motivadora para a desistência do trabalho. Estas categorias foram denominadas "categorias causais" e trazem a informação que corresponde ao foco da pesquisa.

\section{RESULTADOS}

As mulheres entrevistadas possuem baixa escolaridade e faixa etária entre 30 e 40 anos. Os rendimentos mensais obtidos, quando associadas às cooperativas, eram acima do salário mínimo nacional, correspondendo aos valores compatíveis com a remuneração oferecida por outros setores da economia aos trabalhadores com 
baixa escolaridade. Este fato fica evidenciado pelos resultados da análise das entrevistas, que não apontaram a insatisfação com os rendimentos como fator determinante para a desistência da atividade como cooperada.

Conforme resultados obtidos pela pesquisa, percebe-se que os fatores de desistência são vários, como se pode observar no Quadro 1. Este trabalho, no entanto, centralizou sua análise no fator mais evidente mencionado nos relatos fornecidos pelas cooperadas, que aponta a desistência do trabalho por "Problemas familiares", onde a necessidade de cuidar de filhos e parentes foi preponderante para a desistência da atividade nas cooperativas.

Quadro 1 - Fatores preponderantes da desistência do trabalho

\begin{tabular}{|c|c|}
\hline Categoria & Cooperadas \\
\hline Problemas familiares (cuidar do outro). & $8 / 30$ \\
\hline Melhor oportunidade de trabalho. & $3 / 30$ \\
\hline Problemas de saúde. & $3 / 30$ \\
\hline Condições de trabalho precárias e insalubres. & $2 / 30$ \\
\hline Problemas decorrentes da gestação. & $2 / 30$ \\
\hline Orientação médica para deixar o trabalho. & $2 / 30$ \\
\hline Conflitos por decisões administrativas (desvio dos princípios do cooperativismo). & $1 / 30$ \\
\hline Problemas associados ao vício (consumo de álcool). & $1 / 30$ \\
\hline Mudança de endereço. & $1 / 30$ \\
\hline Dificuldades para aceitar críticas e regras. & $1 / 30$ \\
\hline Sentimento de improdutividade. & $1 / 30$ \\
\hline Inadequação momentânea (gestação). & $1 / 30$ \\
\hline Problemas familiares (conflitos) & $1 / 30$ \\
\hline Oposição à política de remuneração. & $1 / 30$ \\
\hline Baixa remuneração. & $1 / 30$ \\
\hline
\end{tabular}

Fonte: elaboração da autora (2015).

A opção por trabalho e renda, obtida nas cooperativas pelas mulheres participantes da pesquisa, embora componha um elemento importante, foi colocada em segundo plano diante da necessidade urgente de atuar como cuidadoras. Muitas vezes a função de mãe, filha e esposa foi priorizada, resultando em inúmeras faltas, seguidas de desistência do trabalho, como pode ser observado nestes depoimentos:

[...] Mas eu saí mesmo, porque meu bebê pegou bronquiolite e eu comecei a faltar muito [...] Agora no momento não tenho ninguém pra cuidar dos meus filhos. $E$ a situação ficou meio complicada (demostra preocupação). O bebê agora que tá melhor, mas tenho que dá um jeito nessas coisa para poder voltar, faz falta porque o dinheiro que eles me pagavam era bom e ajudava bastante comprar as coisas para as crianças, paga aluguel, essas coisa, gasto que a gente tem (Cláudia).

Eu saí porque a minha irmã olhava as criança pra mim, só que ela ficou doente [...]. Mas só que o problema dela piorou, agora ela num tem mais condição mesmo! Nem olhá criança ela aguenta mais. Vou ter que me virar sozinha... (Ana).

[...] Aí acabei num indo mais, que num tinha condição! Tinha dia que ela tava bem, tinha dia que não, e eu correndo com as coisa dela, inté agora num acabei de arrumá tudo ainda... (Júlia).

Além da desistência do trabalho, por problemas familiares, resultante da responsabilidade de cuidar dos filhos, também foram relatadas a necessidade de assistência a outros membros da família, entre eles irmãos, pais e sogra, como se pode conferir neste depoimento: 
[...] mas ele ficou doente e começou a precisá de tratamento, que ele num podia mais beber. Eu num tinha quem tomasse conta dele, que ficasse de olho, vigiando e tive que parar...prá tomá conta dele. Daí eu larguei... (Marina).

A participação deste grupo de mulheres no mercado de trabalho ainda terá de ser conquistada, pois oscilam entre seus compromissos sociais e familiares e a necessidade de trabalho.

Ao desistir da atividade nas cooperativas do Rio Grande do Sul por "problemas familiares", todas as entrevistadas relataram que voltaram a exercer a atividade de coletoras de materiais recicláveis, atuando de forma individual, acumulando principalmente produtos como latinhas e garrafas plásticas, exatamente como faziam antes de ingressar nas cooperativas. Neste sentido, a informalidade do trabalho individual, embora ofereça maior risco à saúde, piores condições de trabalho e menor rendimento, se adequa às condições de dificuldade que esse grupo apresenta para assumir compromissos de expediente frequente.

A opção por atender motivações sociais pode ser explicada, em parte, pela forte necessidade de cuidar e proteger os outros, fator que compõe um exemplo de necessidade social dos seres humanos, resultantes da aprendizagem e experiências pessoais (WEITEN, 2010). Tal fator é agravado pela falta de políticas públicas de apoio, através da oferta de creches e berçários, impondo tais escolhas, impedindo muitas mulheres de exercerem seu potencial como geradoras de renda ao cumprirem seu papel social de cuidadoras. Este problema poderia ser minimizado se as vagas em creches públicas fossem suficientes para atender filhos de mães trabalhadoras, se as próprias cooperativas se organizassem para montar creches para filhos de associados ou se os rendimentos fossem maiores, suficientes para o pagamento por este serviço em instituições privadas.

O desenvolvimento de parcerias que suprissem as necessidades básicas de segurança relacionada ao cuidado com os filhos das cooperadas e permutas com órgãos públicos ou privados também poderia representar um diferencial, ao trocar o serviço de coleta de material reciclável com o trabalho de assistência às crianças filhas das cooperadas. Tais medidas poderiam garantir maior tranquilidade, facilitar o acesso e disponibilidade para o trabalho, reduzindo faltas e, consequentemente, alcançando melhores resultados produtivos e maior satisfação com a atividade nas cooperativas.

\section{CONCLUSÃO}

As cooperativas RS participantes da pesquisa oferecem oportunidades de trabalho às mulheres que vivem à margem da sociedade, excluídas do mercado formal pela baixa escolaridade e pouca qualificação profissional. Em geral, os resultados de produtividade da reciclagem do RS, segundo Magera (2005), menores que $8 \%$, não justificariam sua criação, mas com propósitos políticos e ambientais, muitas foram fundadas nas últimas décadas no Brasil (800 cooperativas).

No entanto, os elevados números do turnover voluntário deste grupo de cooperativas RS estudadas, que corresponde em média a $25 \%$, evidencia um desencontro entre oportunidade de trabalho e expectativas dos trabalhadores. Este quadro demonstra uma realidade, que possivelmente se repete nas demais cooperativas RS do Brasil. No período anterior a um ano de atividade, as pessoas desistem da cooperativa, contrariando a proposta de inserção baseada no desenvolvimento de um trabalho coletivo, segundo princípios de autogestão e participação democrática que fundamentam o cooperativismo. Tais desistências figuram-se com muita clareza nas entrevistas realizadas com as ex-cooperadas. Pessoas que sem capacidade de análise crítica do processo, se inserem nas cooperativas na busca por melhores condições de trabalho.

O grupo de mulheres analisado é composto por pessoas acostumadas a buscar sobrevivência pela execução de atividades que exigem grande esforço físico, colocando em risco seu bem-estar e saúde por uma remuneração baixa, que mal cobre suas necessidades de alimentação e moradia. É incomum que, ao se depararem com uma oportunidade que promova benefícios que visam minimizar a precariedade na qual sobrevivem, ocorra a desistência, seguida pelo retorno à atividade de catadora individual. Ficou claro que este fato se dá pela falta de estrutura de suporte que garanta recursos mínimos de cuidados com seus dependentes, em sua maioria crianças na faixa etária de 0 a 5 anos.

1. Acordo que define e controla os movimentos transfronteiriços de resíduos perigosos e seu depósito. 
O papel desempenhado pelas cooperativas RS, ao buscar reduzir as dificuldades do trabalho informal e individualizado, enfrenta ainda inúmeros desafios internos, impostos pelos entraves dispostos no acesso à tecnologia e na obtenção de recursos a partir da comercialização de produtos que, pela sua composição, detém pouco valor agregado. Como resultado, os benefícios proporcionados pela atividade de cooperada não atingem necessidades básicas, que dependem principalmente de melhorias nos serviços públicos oferecidos aos cidadãos, fazendo com que muitas retornem a antiga condição de dificuldade vivenciada pela atividade de catadora individual.

Portanto, este trabalho nas cooperativas estudadas evidenciou um turnover no segmento feminino que demonstra a sua similaridade com o que ocorre em outras áreas do trabalho no Brasil: salários menores, trabalhos precarizados, falta de incentivos e capacitação. Assim sendo, a contribuição desta pesquisa levará o setor público e privado a olhar com maior parcimônia a mão de obra feminina utilizadas nas cooperativas RS.

Cabe aos municípios ou a entidades privadas realizar parcerias com cooperativas RS, que resultem na oferta de serviços de suporte proporcionando a este grupo de pessoas a tranquilidade e estabilidade necessárias para atuarem de forma mais efetiva na busca de sua sobrevivência.

\section{TURNOVER FEM IN SOLID WASTE COOPERATIVE: A PHENOMENOLOGICAL STUDY ON THE CAUSES}

\section{ABSTRACT}

This study aims to understand the causes of voluntary turnover in a number of solid waste cooperatives, located in the state of São Paulo. For this, we applied the method of hermeneutic phenomenology, identifying through analysis of interviews with former members of the cooperatives, the reasons for the phenomenon of job abandonment in the analyzed units. The factors that emerged from experiments reported refer to difficulties, expectations and dissatisfactions experienced by these agents. This study sought to comprehend the elements that contribute to the alignment of strategic measures to the needs of cooperative members, increasing their degree of commitment and strengthening the process of social inclusion, present in the objectives of solid waste cooperatives.

Keywords: Solid waste. Cooperatives. Job abandonment. Turnover. Waste. Phenomenology.

\section{REFERÊNCIAS}

APPOLINÁRIO, Fábio. Metodologia da Ciência: filosofia e prática da pesquisa. 2. ed. São Paulo: Cengage Learning, 2012.

ASSOCIAÇÃO BRASILEIRA DE EMPRESAS DE LIMPEZA PÚBLICA E RESÍDUOS ESPECIAIS (ABRELPE). Panorama dos Resíduos Sólidos no Brasil 2010. São Paulo: ABRELPE,2010. Disponível em <http://www.abrelpe.org.br/ downloads/Panorama 2010.pdf> Acesso em: 25 set. 2013.

ANTUNES, Ricardo. O Caracol e sua concha: ensaios sobre a nova morfologia do trabalho. São Paulo: Boitempo Editorial, 2005.

BACHMANN \& ASSOCIADOS. 3 Benchmarking Paranaense de Recursos Humanos: Dados de 2010. Curitiba: Bachmann \& Associados, 2011.

BARDIN, Laurence. Análise de conteúdo. 6. ed. Lisboa: Edições 70, 2011.

BRASIL. Ministério do Trabalho e Emprego. Classificação brasileira de ocupações (CBO). [2013]. Disponível em: <http://www.mtecbo.gov.br/cbosite/pages/pesquisas/BuscaPorTituloResultado.jsf>. Acesso em: 2 dez. 2013. 
BERNS, Maurice et al. The business of sustainability: Results and insights from the first annual. MIT Sloan management review global sustainability survey, Cambridge, MA, n. 1, p. 19, vol. 51, 2009. Disponível em: <http://www.bcg.com/documents/file32201.pdf>. Acesso em: 8 out. 2013.

BOAVA, Diego Luíz Teixeira; MACEDO, Fernanda Maria Felício. Contribuição da fenomenologia para estudos organizacionais. [2011]. Disponível em: <http://www.scielo.br/pdf/cebape/v9nspe1/v9nspe1a03. pdf>. Acesso em: 11 ago. 2014.

CEMPRE. Pesquisa Ciclosoft 2012: Radiografando a coleta seletiva. [2012]. Disponível em: <http:// www. cempre.org.br/Ciclosoft2012.pdf> Acesso em: 28 out. 2013.

CENTRO DE REFERÊNCIA EM COOPERATIVISMO E ASSOCIATIVISMO (CRCA) . Evolução dos indicadores. [2012]. Campinas, SP. Disponível em: <http://www.10anoscampinasrecicla.crca.org.br/crca.htm>. Acesso em: 15 jan. 2014.

CERBONE, D. R. Fenomenologia. 2. ed. Petrópolis, RJ: Vozes, 2013.

CESCON, Everaldo. Fenomenologia da consciência e da mente. Caxias do Sul, RS: Educs, 2013.

COPERLÍNEA AMBIENTAL DO BRASIL. Informativo 2013. [2013]. Disponível em: <http://www.cooperativismo. org.br/cooperativismo/noticias/noticia.asp?id=22334>. Acesso em: 11 out. 2013.

COUTO, Gabriela Albanás. Aprendizagem social e formação humana no trabalho cooperativo de catadores(as) em São Paulo. 2012. Dissertação (Mestrado em Educação) - Faculdade de Educação, Universidade de São Paulo, São Paulo, 2012.

CRESWELL, John. Qualitative inquiry and research design: choosing among five traditions. Thousand Oaks: Sage, 1998.

CRESWELL, John. Projeto de pesquisa: métodos qualitativo, quantitativo e misto. 2. ed. Porto Alegre: Bookman, 2010.

DEPARTAMENTO INTERSINDICAL DE ESTATÍSTICA E ESTUDOS SOCIOECONÔMICOS (DIEESE). Rotatividade e Flexibilidade no Mercado de Trabalho. [2011]. Disponível em: <http://www.dieese.org.br/livro/2011/ livroRotatividade11.pdf>. Acesso em: 13 dez. 2014.

GAMA, Carlos Alberto Pegolo da; KODA, Mirna Yamazato. Cooperativismo e reciclagem de resíduos sólidos: uma reflexão a partir da psicanálise de grupos. Cadernos de Psicologia Social do Trabalho, São Paulo, v. 13, n. 2, p. 209-224, 2010.

GIBSON, Sharon. K.; Hanes, Lisa. A. The contribution of phenomenology to HRD research. Human Resource Development Review, Thousand Oaks USA, v. 2, n. 2, p. 181-205, 2003.

KRIKKE, H. R; VAN HARTEN, A; SCHUUR, P. C. On a medium term product recovery and disposal strategy for durable assembly products. International Journal of Production Research, San Francisco USA, v. 36, n. 1, p. 111-139, 1998.

LEE, Tomas W; MITCHELL, Terence R. An alternative approach: The unfolding model of voluntary employee turnover. Academy of Management, Briarcliff Manor, v. 19, n. 1, p. 51- 89, 1994.

LIMA, Maria Isabel Bezerra de. Cooperativas de Reciclagem de Santo André: Conquistas e Dificuldades.

Universidade Federal do ABC. [2011]. Disponível em: <file://C:/Users/joelma/Desktop/Cooperativas\%20de\%20 
Reciclagem\%20de\%20Sano\%20Andr\%C3\%A9\%20\%20Conquistas\%20e\%20Dificuldades\%20\%20(rotatividade). htm>. Acesso em: 2 fev. 2014.

MAGERA, Márcio. Os empresários do lixo: um paradoxo da modernidade. 2. ed. Campinas: Átomo Alínea, 2005.

MAGERA, Márcio. Os caminhos do lixo: da obsolescência programada à logística reversa. Campinas: Átomo Alínea, 2013.

MARTINS, Joel. Um enfoque fenomenológico do currículo: educação como poésis. São Paulo: Cortez, 1992.

MERIGHI, Miriam Aparecida Barbosa; GONÇALVES, Roselane; FERREIRA, Fernanda Cristina. Bibliometric study on nursing theses and dissertations employing a phenomenological approach: tendency and perspectives.

Rev. Latino-Am. Enfermagem [online], v.15, n. 4, p. 645-650, 2007. Disponível em: <http://dx.doi.org/10.1590/ S0104-11692007000400019>. Acesso em: 5 out. 2013.

PAULA, Mabel Bastos de; SOUZA-PINTO, Helma de; SOUZA, Maria Teresa Saraiva de. A importância das cooperativas de reciclagem na consolidação dos canais reversos de resíduos sólidos urnanos pósconsumo. [2010]. Disponível em: < http://www.simpoi.fgvsp.br/arquivo/2010/artigos/e2010_t00221_ pcn41182.pdf > . Acesso em: 28 set. 2015.

SALGADO, Gabriel; TEIXEIRA, Thiago. Catadores(as) e a metrópole: identidade, processo e luta. [2012]. Disponível em: <http://catadoreseametropole.wordpress.com/baixe-o-livro-2/>. Acesso em: 10 out. 2013.

SILVA, Anielson Barbosa da. A fenomenologia como método de pesquisa em estudos organizacionais. In: GODOI, C.K.; BANDEIRA-DE-MELLO, R.B.; SILVA, A.B. (Org.). Pesquisa Qualitativa em Estudos Organizacionais. São Paulo: Saraiva, 2010. p. 267-297.

SINGER, Paul. A Recente Ressurreição da Economia Solidária no Brasil. Breve introdução conceitual. [2002]. Disponível em: <www.uff.br/incubadoraecosol/docs/ecosolv2.pdf> Acesso em: 18 out. 2013.

SORDI, José Osvaldo de. Elaboração de Pesquisa Científica: seleção, leitura e redação. São Paulo: Saraiva, 2013.

SOUZA, Maria Tereza Saraiva de; PAULA, Mabel Bastos de; SOUZA-PINTO, Helma de. O papel das cooperativas de reciclagem nos canais reversos pós-consumo. Rev. adm. Empres, [online], v. 52, n. 2, p. 246-262, 2012. Disponível em: <http://dx.doi.org/10.1590/S0034-75902012000200010>. Acesso em: 2 fev. 2014.

TARALLO, Fernando. A Pesquisa Sociolinguística. São Paulo: Ática, 1986.

VANDENBERG, Robert J. Desegregating the Motives Underlying Turnover Intentions: When do Intentions Predict Turnover Behavior? Human Relations, New York USA,1999. Disponível em: <httt://www.findar ticles.com>. Acesso em: 11 out. 2013.

VAN MANEN, Max. Researching lived experience: human science for an action sensitive pedagogy. New York: State University of New York Press, 1990.

WAUGH JR., Willian L.; WAUGH, Willian L. Phenomenology and public administration. International Journal of Organization Theory and Behavior, Boca Raton, v. 7, n. 3, p. 405-431, Fall 2004. 
Joelma Telesi Pacheco Conceição; Márcio Magera Conceição; Alexandre Martinewski

WEITEN, W. Introdução à psicologia: temas e variações. São Paulo: Cengage Learning, 2010.

WOMEN IN INFORMAL EMPLOYMENT: GLOBALIZING AND ORGANIZING (WIEGO). Enfocándonos en las trabajadoras informales: recicladoras de basura. [2009]. Disponível em: <http://www.wiego.org/WIEGO_ En_Espanol/publicaciones/FactSheet-Rec-Spanish.pdf>. Acesso em: 30 out. 2013. 